(2) Open Access Full Text Article

REVIEW

\title{
Cognitive Behavioral Therapy for People with Chronic Obstructive Pulmonary Disease: Rapid Review
}

This article was published in the following Dove Press journal: International Journal of Chronic Obstructive Pulmonary Disease

\section{Marie T Williams $\mathbb{D}^{\prime}$ \\ Kylie N Johnston (D)' \\ Catherine Paquet $\mathbb{D}^{2}$}

'Innovation, Implementation and Clinical Translation in Health (IIMPACT), School of Health Sciences, University of South Australia, Adelaide, SA 5000, Australia; ${ }^{2}$ Australian Centre of Precision Health, School of Health Sciences, University of South Australia, Adelaide, SA 5000,

Australia
Correspondence: Marie T Williams Innovation, Implementation and Clinical Translation in Health (IIMPACT), Schoo of Health Sciences, University of South Australia, North Terrace, Adelaide, SA 5000, Australia

Email Marie.williams@unisa.edu.au

\begin{abstract}
Cognitive behavioral therapy (CBT) is increasingly recommended in the management of people living with chronic obstructive pulmonary disease (COPD). This rapid review presents the evidence base for CBT for people with COPD and describes 1) the nature of CBT interventions and comparators in controlled trials (high or low resource intensity); and 2) factors influencing intervention effects on health outcomes (anxiety, depression, breathlessness, quality of life and exercise capacity). Primary studies reporting CBT interventions in adults with COPD were identified with data extracted by a single reviewer $(20 \%$ of studies checked for data accuracy). Studies were synthesized descriptively with meta-analyses (random effects models) of controlled trials undertaken to report mean standardized effect sizes $(95 \% \mathrm{CI})$ for health outcomes. Random effects meta-regression models explored whether CBT target, intervention dosage, intensity, facilitator profession, delivery mode, clinically significant anxiety/depression, trial design/quality and sample size predicted effect size. The search identified 33 primary studies published between 1996 and 2019 (controlled trials $n=24$, single group cohort $n=6$, case exemplars $n=2$, phenomenological $n=1$ ). Controlled trials frequently compared high-intensity CBT interventions against enhanced/ usual care $(n=12)$ or high-intensity CBT interventions against high-intensity comparators $(n=11)$. When all controlled studies were included, small, significant improvements favoring CBT were evident across all health outcomes (SMD ranged from -0.27 to $0.35, \mathrm{p}<0.05$ ). When intensity dyads were considered, significant improvements were evident only when high-intensity CBT interventions were compared to enhanced usual care/usual care (SMDs ranged from -0.45 to $0.54, \mathrm{p}<0.05$ ). No other variable consistently predicted intervention effect sizes across all health outcomes. Overall, the evidence base supports the use of CBT for a range of health outcomes in people with COPD. Consistent benefits were evident when high-resource-intensive CBT interventions were compared to usual care. Low-resourceintensity CBT warrants further investigation in settings where cost of comprehensive care is prohibitive.
\end{abstract}

Keywords: cognitive behavioral therapy, chronic obstructive pulmonary disease, rapid review

\section{Introduction}

Cognitive behavioral therapy (CBT) is the broad term used to describe a range of therapies arising from cognitive behavioral models of anxiety disorders. ${ }^{1}$ Within these therapeutic approaches, the person and therapist work collaboratively to 1) identify maladaptive thoughts, beliefs and impact of current symptoms or feelings; 2) develop skills to identify, monitor and counteract problematic cognitions related 
to the specific symptom; and 3) build a repertoire of coping skills appropriate to the target thoughts, beliefs, and behaviors. ${ }^{1}$ In adults with generalized anxiety, panic disorders, and depression, high level evidence underpins recommendations within clinical guidelines for the use of CBT as part of management, ${ }^{1,2}$ where CBT interventions should 1) be based on treatment manuals used in clinical trials; 2) be delivered by trained and competent practitioners; and 3) usually consist of 12-15 weekly sessions (each lasting an hour) with duration of therapy adjusted pending responsiveness. ${ }^{1}$

For generalized anxiety and depressive disorders, a stepped approach to management is recommended where the least intrusive and most effective intervention (non-pharmacological with or without pharmacotherapy) is devised in collaboration with the patient based on severity of the disorder, previous response to management, availability and patient preference. $^{1,3}$ In general, stepped approaches move from least intrusive options (education about the disorder and active monitoring) to low-resource-intensive interventions (individual self-help such as written or electronic self-help materials (bibliotherapy) with no or minimal therapist involvement and psychoeducational groups). Where there is minimal response or symptoms are more severe, high-resource-intensive interventions are considered (therapist facilitated individual CBT, applied relaxation, psychodynamic therapy, non-directive therapies and counselling, or more specialized and complex psychological treatments) with or without pharmacotherapy. ${ }^{1,3}$

In people living with COPD, anxiety and depression are comorbidities associated with poorer prognosis. ${ }^{4}$ In this population, a range of systematic reviews have been published specific to the impact of psychological interventions on psychological (anxiety, depression, quality of life) $)^{5-10}$ or psychological and physical health outcomes. ${ }^{11,12}$ Pending the intent, eligibility criteria, and publication dates, a number of studies denoted as including a CBT intervention recur throughout these reviews. ${ }^{13-22}$ These studies delivered CBT as either the sole intervention ${ }^{1,9,20-22,81}$ or in combination with pulmonary rehabilitation ${ }^{13,15,16}$ with comparators ranging from usual care ${ }^{13,18-20,22}$ to other active high resource interventions. $^{13-17,21}$ Of the reviews that include meta-analysis or subgroup analysis of randomized controlled trials (RCTs) specific to CBT interventions, findings are inconsistent, concluding both in favor of CBT against comparators for psychological outcomes (depressive symptoms: $n=12 ;^{6}$ $\mathrm{n}=10 ;^{12}$ anxiety symptoms $\mathrm{n}=3,{ }^{11} \mathrm{n}=3^{9}$ ) or alternatively reporting no significant difference between CBT intervention and comparators $\left(n=7 ;^{7} n=4 ;^{8} \mathrm{n}=11^{10}\right)$. Consequently, clinical practice guidelines for management of COPD offer a range of recommendations concerning the role or potential role of CBT for anxiety, depression, breathlessness, quality of life, or functional exercise capacity. ${ }^{4,23}$

Unlike the stepped approach recommended for management of anxiety and depression in the general population, CBT interventions for people with COPD are rarely classified in terms of resource intensity of the intervention. It is also unclear whether the inclusion of CBT within high resource interventions such as pulmonary rehabilitation, produces a greater health benefit compared to the CBT alone, other high-resource interventions, low-resource interventions, or usual care.

In this rapid review we were interested to describe the evidence base of primary studies, irrespective of research approach, concerning use of CBT in people living with COPD. For controlled trials we aimed to:

1. describe the nature of CBT intervention and comparators (low vs high intensity) and

2. explore factors influencing intervention effect (effect sizes) for health outcome domains of anxiety, depression, breathlessness, quality of life, and exercise capacity.

For trials comparing CBT with usual care, we hypothesized that effect sizes would vary as a function of intervention: comparator intensity, with the largest between-group effects sizes likely to be present with the greatest contrasts in intensity between intervention and comparator (eg, highintensity CBT interventions vs usual care comparators) and the smallest effect sizes between CBT interventions and comparators of similar intensity (eg, high-intensity CBT vs high-intensity comparator).

\section{Methods}

This rapid review used a range of approaches to identify primary studies of CBT interventions in people with COPD. We reviewed 1) articles excluded as CBT interventions as part of a prior systematic review of health counselling interventions for people with COPD (PROSPERO 2016: CRD42016046415 ${ }^{24}$ ); 2) prior systematic/critical reviews concerning psychological interventions for people living with COPD to identify studies where the intervention was described as CBT; 3) citations of studies identified as including a CBT intervention to identify more recent publications. In addition, we undertook a limited search of publicly available databases (October 2019, Medline, 
Medline: epub ahead of print and Scopus; title and abstract including the terms CBT and COPD). Reference lists of included studies and systematic reviews identified during the search were reviewed to identify additional potentially relevant studies.

Studies were eligible for inclusion in this review if: 1) the original primary study was available as full text and published in English; 2) participants included adults with a physician or spirometric diagnosis of COPD, irrespective of disease severity or comorbidities; 3 ) the term "cognitive behavioural therapy" was used when describing the intervention either as a component of a multifaceted intervention or as a single stand-alone intervention irrespective of mode of delivery (individual vs group, home vs health setting, face to face, phone or electronic delivery). All study designs (experimental, observational or qualitative frameworks) were eligible for inclusion.

Studies were excluded where: 1) participants exclusively had a primary pulmonary condition other than COPD (asthma, interstitial lung disease, idiopathic fibrosis); 2) COPD data were not reported separately to other chronic conditions; 3 ) studies concerned additional or sub-analysis of primary study data (to avoid data duplication); and 4) records were conference abstracts, study protocols, commentaries or narrative reviews (reviews, editorials, letters).

Full text versions of each eligible study were screened by a single reviewer (MTW) against a priori eligibility criteria. Where studies could not be confidently included/ excluded, independent review and advice was sought (CP, $\mathrm{KNJ}$ ) and/or authors contacted for clarification. Where full text papers reported secondary analysis of an RCT the original parent study was sought. A data extraction template was developed prospectively, data were extracted by a single reviewer (MTW) with $20 \%$ of eligible studies, randomly checked for data accuracy $(\mathrm{CP})$.

Data extracted from eligible studies included publication demographics (year of publication, country of data source, study design) and participants (group mean and standard deviation (SD) for age, sex ratio, presence and nature of threshold criterion for anxiety or depression, sample size included in analysis). Details of the CBT intervention and comparator included CBT target/intent, sole or part of a complex intervention (exercise/pulmonary rehabilitation, health education), format (individual, group, face-toface, telephone, computer-based), supporting resources (phone, print/audio materials); nature of the comparator (eg usual care, wait-listed, social group control, education), number of sessions (maximum possible), attendance, duration of sessions (minutes), duration of intervention program (weeks), professional discipline of facilitator [Objective 1].

The primary health outcomes of interest in this review spanned five health domains: anxiety, depression, breathlessness, quality of life and exercise capacity. Where authors reported both a total and subdomain scores for an outcome measure, the subdomain score was used in preference to the total score where appropriate (eg Hospital Anxiety and Depression scale (HADS)- subdomain scores for HADSAnxiety or HADS-Depression used rather than HADS-total score). Wherever possible, the ATS guideline for dyspnea was used to guide domain choice for breathlessness outcomes. ${ }^{25}$ Where a breathlessness instrument assessed sensory-perceptual (intensity or quality) or affective distress (discomfort), the outcome was allocated to the breathlessness domain (eg, Chronic Respiratory Questionnaire - Dyspnea subscore, ${ }^{25}$ Interpretation of Breathing Problems Questionnaire $\left.^{26}\right)$. Where the breathlessness instrument combined breathlessness with other symptoms (cough, wheeze, secretions) and assessed impact on functional performance/ activity or health-related quality of life, the outcome was allocated to the quality-of-life domain (eg, COPD Assessment Test (CAT), ${ }^{25}$ St George Respiratory Questionnaire, ${ }^{25}$ COPD Self-Efficacy scale ${ }^{27}$ ). Quality-oflife subdomain scores related to mental wellbeing (SF-36 Mental Component Score (MCS), CRQ-Mastery) and physical (SF-36 Physical Component Score (PCS), CRQFatigue) health were used where available. Otherwise, total quality-of-life scores were used.

Where reported, data were extracted at baseline and after intervention with post-intervention follow-up assessments categorized as immediate (within 1 week to 1 month), short-term ( 2 to 6 months) and longer-term ( $>6$ to 12 months). The analysis reported in this review considers only immediate post intervention outcomes. Where studies reported two time points within the post-intervention followup assessment categories, we chose the assessment at the most distant follow-up point. Within- and between-group differences (effect sizes) for primary outcomes - where reported - were extracted from the study or calculated if sufficient data were reported. Where outcome data were presented predominately in figures, online software $\left(\right.$ Digiplot $^{28}$ ) was used.

\section{Data Management and Synthesis}

Descriptive summaries of data extracted from each study were created. CBT interventions (and comparators) were 
categorized into one of three categories; 1) high-intensity; 2) low-intensity; and 3) usual care (UC) or enhanced usual care (EUC). There is no universally agreed definition for low- and high-intensity psychological interventions. ${ }^{1}$ The general principle of these categorizations concern resource implications rather than time required by an individual to complete the intervention. In this review we used the following definitions for both the active CBT intervention and comparators (where appropriate):

Low intensity $=$ minimal (or no) involvement of a health professional. Where a health professional was involved these reflected psychological disciplines or other health professional discipline trained in the provision of CBT. These self-help interventions could include individual written or electronic self-help materials (bibliotherapy) and psychoeducational groups. Unless otherwise reported, it was assumed that low-intensity interventions (or comparators) represented additional activities provided on a background of usual care.

High intensity $=$ majority of sessions (individual or group) were facilitated by a health professional from a psychological discipline or other health professional discipline trained in the provision of CBT. The CBT intervention included a direct intent to target and facilitate change in an individual's maladaptive cognitions/beliefs and related behaviors as a key focus or component within the CBT intervention. Unless otherwise reported, it was assumed that high-intensity interventions (or comparators) represented additional activities provided on a background of usual care.

Usual care or enhanced usual care $=$ In trial comparator groups consisting of usual care or enhanced usual care, we acknowledged that all interactions with health-care professionals or services have the potential to modify, maintain or extinguish an individual's beliefs and related behaviors but there was no reported intentional strategy described to facilitate this change. Therefore, UC was defined as the health care expected or recommended for people living with COPD (with or without reporting of participation in pulmonary rehabilitation and pharmacotherapies and including wait list control). In contrast, EUC included reporting of activities specifically designed for the study to balance researcher contact with participants in the active intervention. These could include scheduling of appointments or phone calls for additional health or wellbeing assessments.

Meta-analysis was undertaken for controlled clinical trials (CCT/RCTs) that reported sufficient data to calculate effect sizes within each outcome domain (anxiety, depression, breathlessness, quality of life and exercise capacity). Controlled studies were appraised for methodological quality using the Physiotherapy Evidence Database scale for RCTs (11 items, score range 0 to 10 with higher scores indicating higher quality). ${ }^{29,30}$ Where data were not reported or unable to be calculated, the study was excluded from further analysis (ie, missing data were not imputed or estimated). When the control/comparator group was used for multiple interventions, the sample size of the control/ comparator group was divided by two to avoid double counting. Meta-analyses using random effects model were performed using the admetan function in STATA v.15.1 (StataCorp, College Station, TX, USA) ${ }^{31}$ and displayed as Forest plots. Heterogeneity was assessed using $\mathrm{I}^{2}$ index and the $\mathrm{Q}$ statistic. Heterogeneity for $\mathrm{I}^{2}$ was interpreted as; 0-40\% might not be important, 30-60\% may represent moderate heterogeneity, 50-90\% may represent substantial heterogeneity, $75-100 \%$ considerable heterogeneity. ${ }^{32}$

To explore factors influencing intervention effect (effect sizes) for health outcomes (Objective 2), random-effects meta-regression models estimated effect sizes for specific predictor variables (moderators) using the MetaReg command in STATA. ${ }^{31}$ In selecting our predictor variables, we were guided by prior meta-regression of CBT interventions specific to people with COPD ${ }^{12}$ or older adults. ${ }^{33,34}$ Given the variability in the way CBT has been delivered, our primary interest was to explore predictors of effect size reflecting resource intensity dyads, and protocol components of both the CBT intervention and comparator, rather than participant characteristics. ${ }^{12,33,34}$ Models were run separately for each outcome category, unless the number of studies was too low $(<10) .^{32}$ Analyses were done separately for quality-of-life mental wellbeing and physical domains, with overall scores being used in both analyses for studies for which subdomain scores were not available. Separate models were estimated for the following list of predictor variables, which were defined a priori: intervention dosage in absolute terms (number of intervention sessions) and relative to comparator (ratio of intervention sessions/comparison sessions); CBT proportional dosage (CBT sessions as proportion of total intervention sessions); intensity of comparison (low or high with $\mathrm{UC} / \mathrm{EUC}$ as reference group), facilitator (psychology professional only or not), inclusion threshold for anxiety/depression (yes, no), CBT mode (individual + group or group with individual as reference group), sample size included in analysis (continuous and as categories: $31-60$, or $\geq 60$ with $\leq 30$ as reference 
group), CBT intervention target (specific psychological focus (SPF) on symptoms (anxiety, depression, breathlessness) or self-management (SM) which included anxiety, depression, symptoms as part of a broader cognitive/behavior skill set). Two additional predictors were included following appraisal of CCT/RCT quality; study design (CCT with RCT as comparator) and quality appraisal score (PEDro score as a continuous variable). Alpha was set at 0.05 .

\section{Results}

Following the search and screening strategy, 33 studies published as full text between 1996 and 2019 were identified which reported outcomes for a CBT intervention for people with COPD. Across all included studies there were 3,215 participants (61\% male) with a mean age 67 years (range 40 to 86). Details of study characteristics are presented in Supplemental materials Table S1. The majority of studies were controlled trials (ie, CCT or RCT $n=24$ ). ${ }^{13-22,35-48} \mathrm{In}$ addition, there were six single group cohort designs, ${ }^{49-54}$ two papers reported case exemplars ${ }^{55,56}$ and one a phenomenological study. ${ }^{57}$ Eight studies were not included as they reported the sub-analysis of a parent study. ${ }^{58-65}$

The majority of studies exclusively recruited people with COPD $(78.7 \%, n=26)$. With the exception of Blumenthal et $\mathrm{al}^{48}$ where $42 \%$ of participants had COPD, in the remaining seven studies, at least half the sample analyzed were categorized as COPD (Cully et al (75\%), ${ }^{41}$ Pumar et al $(75 \%),{ }^{38}$ Cully et al $(74 \%),{ }^{52}$ Cully et al $(66 \%),{ }^{56}$ Jonker et al $(51 \%),{ }^{45}$ Malpass et al $\left.(50 \%)^{57}\right)$. In studies reporting threshold criteria as an eligibility requirement $(\mathrm{n}=15,45 \%)$, these ranged between including people with at least mild-to-moderate anxiety or depression (HADs-A $\geq 8$, Beck Anxiety Inventory (BAI) scores $10-18$, Beck Depression Inventory (BDI) $\geq 13$ ) or clinically significant symptoms (State-Trait Anxiety Inventory STAI-STAIT $\geq 39$, Patient Health Questionnaire PHQ-9 $\geq 10$ ). The majority of studies reported an outcome for anxiety $(\mathrm{n}=30,91 \%$, commonest instrument: HADs-A $\mathrm{n}=7$ studies with one study reporting HADS-Total), depression ( $\mathrm{n}=29,88 \%$, commonest instruments: HADs$\mathrm{D} n=8$ studies) and health-related quality of life $(\mathrm{n}=27$, $82 \%$, commonest instrument: SGRQ $\mathrm{n}=8$ studies). Outcome measures for breathlessness and exercise capacity were reported by just over a third of the studies (both $\mathrm{n}=1236 \%$ ) with the CRQ-dyspnea sub domain scores (5 studies) and 6-minute walk distance (9 studies) the most frequent assessments reported.
Details of CBT interventions and comparators for experimental study designs is presented in Supplemental materials Table S2 (studies $\mathrm{n}=30$; two studies included two interventions against a comparator; active comparator data sets $\left.\mathrm{n}=32^{13,16}\right)$. Study quality scores ranged between 3 and 8 (mean $6 \pm 1$ ) with CCTs scoring consistently lower than RCTS (mean $3 \pm 1$ vs 6 \pm 1 ) (details presented in Supplemental materials, Table S3). The majority of CBT interventions $(\mathrm{n}=22,68 \%)$ had a specific psychological focus (anxiety, depression or symptom) with the remaining interventions including CBT as part of, or to facilitate chronic condition self-management. Interventions in eight studies provided 12 or more sessions of CBT in line with recommendations for generalized anxiety disorders (12-15 sessions ${ }^{1}$ ), with 22 studies providing $\leq 10$ sessions of CBT (which could potentially be defined as a brief CBT). While there was variation between studies, where reported, $\mathrm{CBT}$ interventions were more commonly provided by psychology professionals alone or in concert with other professionals (21 studies), to individuals rather than groups (19 vs 10 studies), with direct face-to-face contact rather than phone/telemedicine (24 vs 2 studies), weekly rather than less frequently (19 vs 9 studies) and for $\geq 60$ minutes rather than shorter durations (19 vs 7 studies). CBT interventions were commonly delivered as the sole intervention (17 studies) or in combination with exercise/ pulmonary rehabilitation with or without additional education (10 and 8 studies respectively).

Within CCT/RCTs, high-intensity CBT interventions predominated within active intervention groups (23/32 groups) with comparator groups reflecting a range of intensities ( $\mathrm{EUC} / \mathrm{UC} \mathrm{n}=12$, high-intensity $\mathrm{n}=9$, low-intensity $\mathrm{n}=3)$. The most common comparator was EUC/UC (12 studies including two studies where pulmonary rehabilitation was available as part of $\mathrm{UC}^{19,43}$ ) followed by exercise/ pulmonary rehabilitation with or without additional education (6 and 2 studies respectively Table S2). For CCT/ RCTs, it was more common to compare high-intensity CBT interventions against EUC/UC $(n=12)$ and high-intensity interventions against high-intensity comparators $(\mathrm{n}=11)$. Single studies reflected comparisons of high-intensity interventions against low-intensity comparators, low-intensity interventions against low-intensity comparators or lowintensity interventions against EUC/UC (Table S2).

Figure 1 presents meta-analyses outcomes for each health domain for the immediate post-intervention follow-up. In studies which included a threshold criterion for anxiety or depression (Table S1 and Table S2), participants allocated to CBT intervention or comparator 
groups did not differ significantly at baseline for anxiety/ depression scores with the exception of Eiser et $\mathrm{al}^{37}$ where, by design, the treatment group had significantly higher anxiety than the comparator group (HADS-A $12 \pm$ 4 vs $7 \pm 3, p<0.01)$. See sensitivity analysis for the impact of excluding Eiser et $\mathrm{al}^{37}$ as one of the two CCTS's ${ }^{36,37}$ included within the original meta-analysis models.

Data for anxiety was available for 20 studies with two studies reporting two active interventions. ${ }^{13,16}$ While considerable heterogeneity existed across studies, overall, CBT interventions were associated with small, significant improvements in anxiety (SMD $-0.25,95 \%$ confidence intervals $-0.41,-0.09, \mathrm{p}=0.002, \mathrm{I}^{2}=70.5 \%$ ). With respect to intensity dyads (excluding categories where a single study was represented), significant improvements for anxiety were noted only when high-intensity CBT interventions were compared to EUC/UC (10 studies; SMD = $-0.25,95 \% \mathrm{CI}-0.44,-0.06, \mathrm{p}=0.011, \mathrm{I}^{2}=62.9 .1 \%$ ).

A similar pattern was seen across all health outcomes. When all studies were included, overall small, significant improvements favoring CBT were evident (Depression $\mathrm{n}=18$ studies, SMD $-0.27,95 \%$ CI $-0.38,-0.17$, $\mathrm{p}<0.0001, \mathrm{I}^{2}=24.1 \%$; Breathlessness $\mathrm{n}=7$ studies, SMD $-0.24,95 \%$ CI $-0.47,0.00, \mathrm{p}=0.045, \mathrm{I}^{2}=70.7 \%$; Quality of life-Mental Wellbeing $\mathrm{n}=16$ studies SMD $0.28,95 \% \mathrm{CI}$ $0.15,0.42, \mathrm{p}<0.0001, \mathrm{I}^{2}=44.8 \%$; Quality of life-Physical

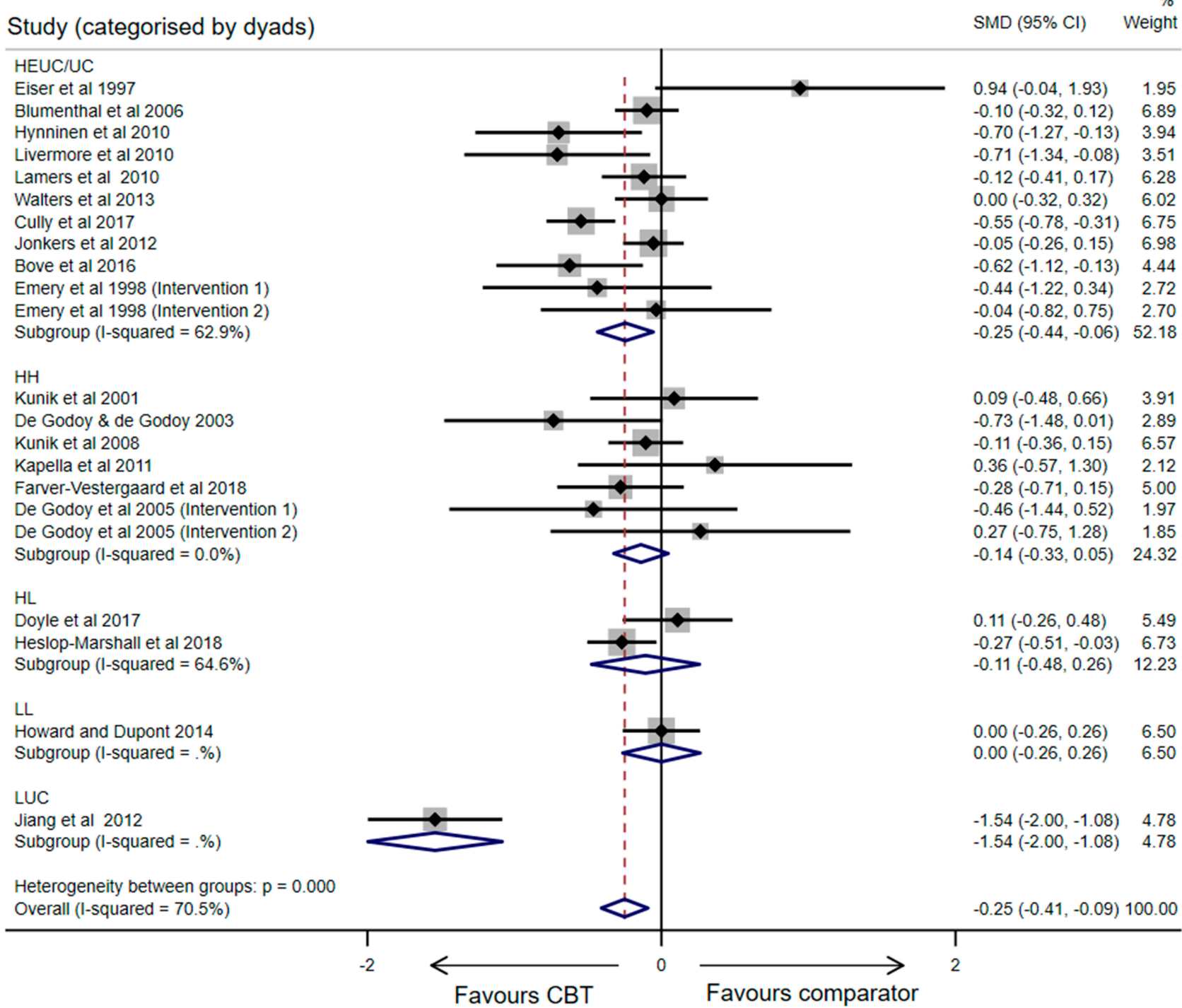

Figure I Continued. 
B Depression

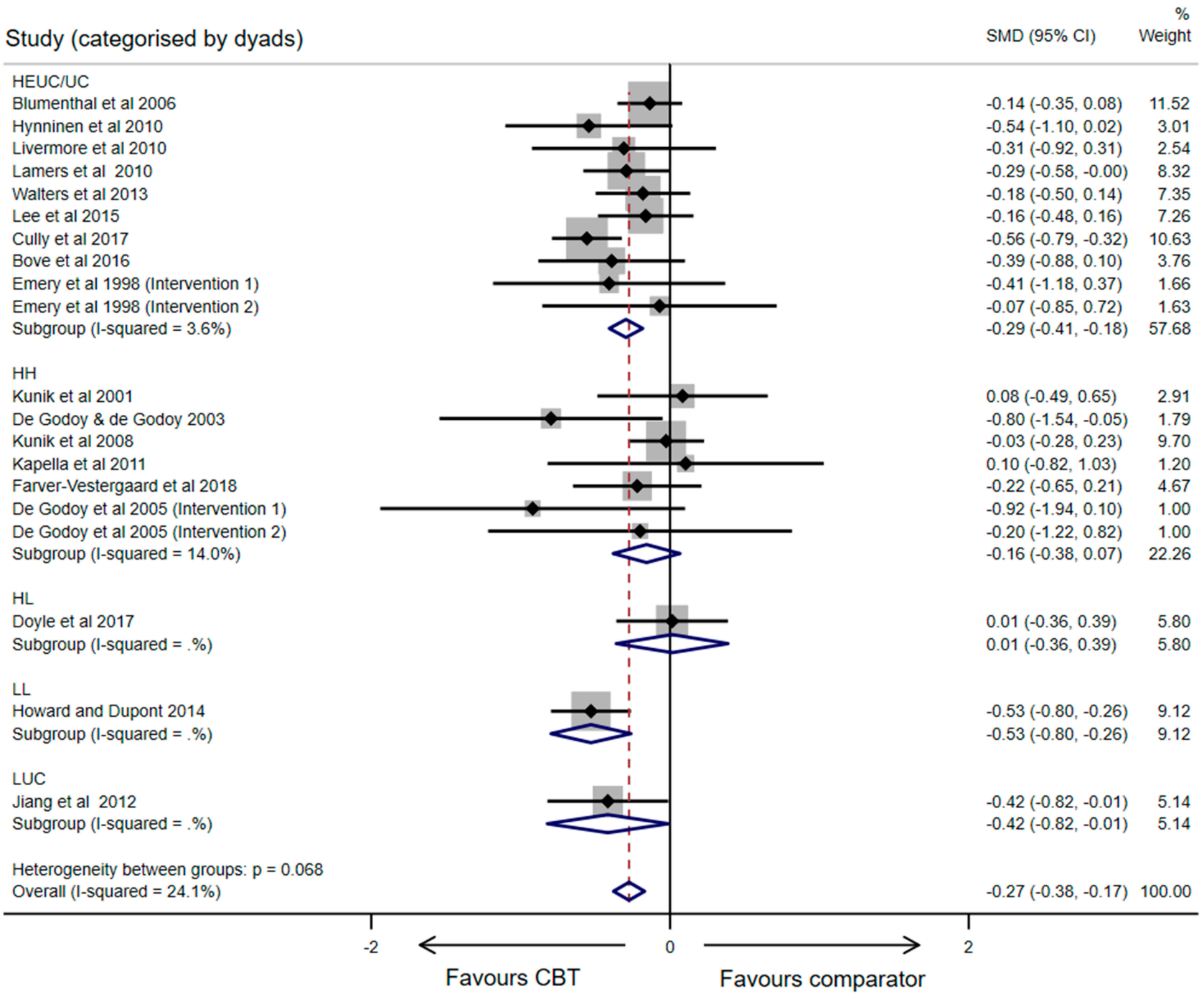

Figure I Continued.

$\mathrm{n}=17$ studies SMD $0.35,95 \%$ CI $0.02,0.69, \mathrm{p}=0.037$, $\mathrm{I}^{2}=91.6 \%$ ). Our conservative approach to avoid double counting (halving sample sizes where studies included more than a single active intervention) might explain the findings for exercise capacity which favored CBT but did not reach significance $(n=7$ studies SMD $0.16,95 \%$ CI $-0.02,0.35, \mathrm{p}=0.089, \mathrm{I}^{2}=0.0 \%$ ).

When intensity dyads were considered (and excluding categories where a single study was represented), significant improvements were evident only when high-intensity CBT interventions were compared to EUC/UC (Depression SMD $-0.29, \quad 95 \% \quad$ CI $-0.41,-0.18$, $\mathrm{p}<0.0001, \mathrm{I}^{2}=3.6 \%$; Breathlessness SMD $-0.45,95 \% \mathrm{CI}$ $-0.86,-0.05, \mathrm{p}=0.028, \mathrm{I}^{2}=77.7 \%$; Exercise capacity SMD
0.54, 95\% CI 0.06, 1.03, p $=0.028, \mathrm{I}^{2}=0.0 \%$; Quality of life-Mental Wellbeing SMD 0.40, 95\% CI 0.20, 0.61, $\mathrm{p}=0.001, \mathrm{I}^{2}=57.0 \%$; Quality of life-Physical SMD 0.31 , $95 \%$ CI $0.11,0.51, \mathrm{p}=0.002, \mathrm{I}^{2}=54.6 \%$ ).

\section{Meta-Regression}

Table 1 presents a summary of the findings from the metaregression (not attempted for breathlessness or exercise capacity as $<10$ studies $^{32}$ ). With the exception of two variables, no other factors significantly predicted intervention effect. The ratio of intervention to comparator sessions was a significant predictor of intervention effect for Anxiety $(-0.11,95 \%$ CI $-0.18,-0.04, p=0.005)$ and Quality of Life-Mental Wellbeing $(0.11$, 95\% CI 0.04 , 


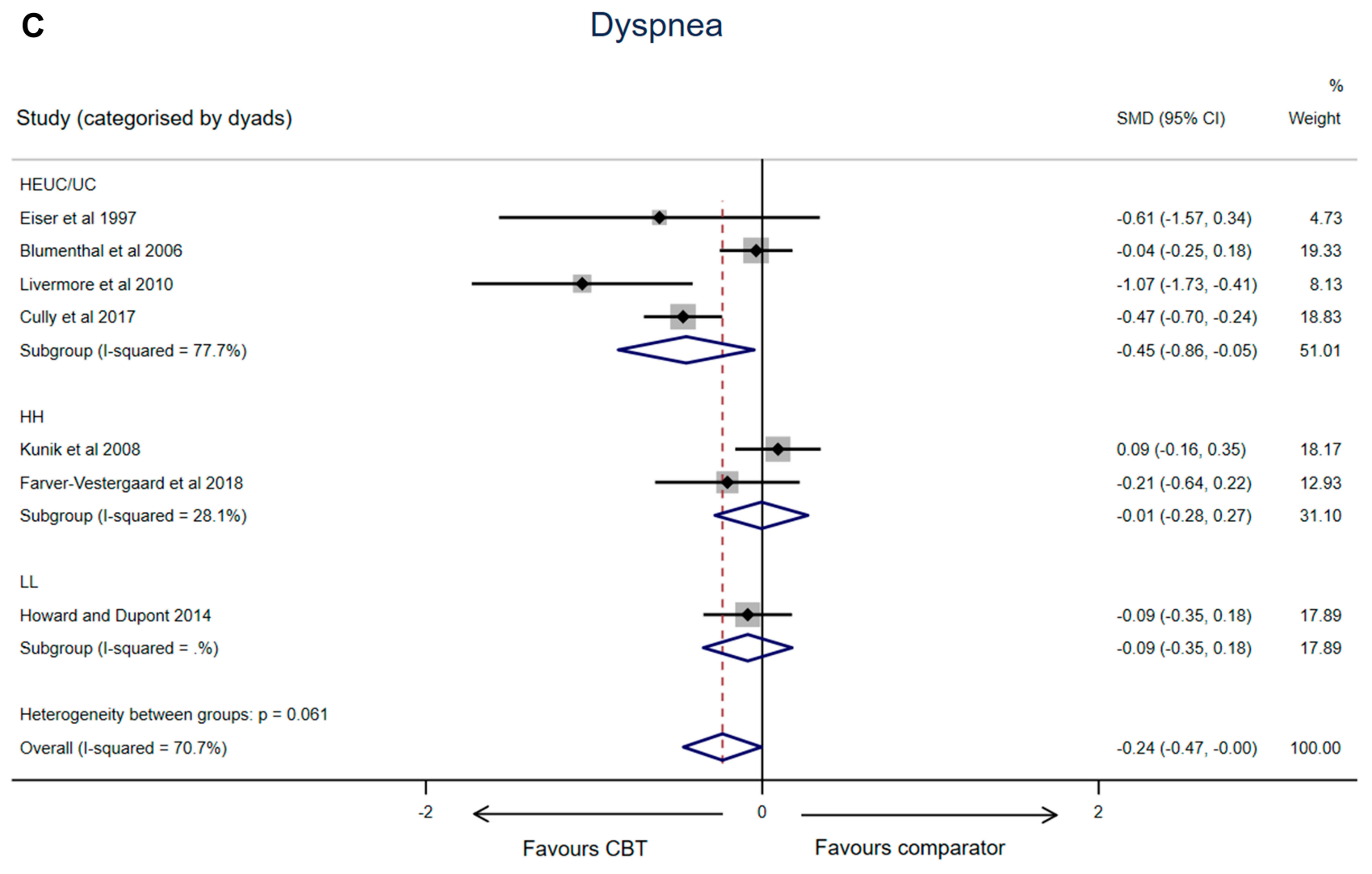

Figure I Continued.

$0.19), \mathrm{p}=0.005)$. For these two health domains, effect size and direction of effect were the same; stronger effects when the ratio of intervention to comparator sessions was higher. For Quality of Life-Physical, the intervention effect size was stronger for low-intensity comparators compared to EUC/UC (1.07, 95\% CI 0.09, 2.06, p= 0.03).

\section{Sensitivity Analysis}

Of the three CCTs included within the review, one ${ }^{35}$ did not contribute data to meta-analysis/regression models. The two remaining CCTs reflected different resource dyads (high intensity resource vs high intensity resource ${ }^{36}$ and highintensity resource vs enhanced/usual care $^{37}$ ) with neither contributing data for Depression. Revised models were run for Anxiety and Breathlessness (excluding Eiser et $\mathrm{al}^{37}$ ), and Exercise Capacity, Quality of life-Mental Wellbeing and Quality of life-Physical, (excluding both Eiser et $\mathrm{al}^{37}$ and Williams et $\mathrm{al}^{36}$ ).

When these CCTs were excluded, standardized mean differences (Effect size) and heterogeneity $\left(\mathrm{I}^{2}\right)$ were essentially unchanged across health outcomes (Dyad and Overall) (see Table S4). Significant differences in between-group effects were no longer present for the high-intensity resource vs enhanced/usual care dyad for breathlessness (SMD $-0.44,95 \%$ CI $-0.89,0.02$ ) or Exercise capacity (SMD $0.59,95 \%$ CI $-0.02,1.20$ ). The significant overall between-group effects (pooled) were no longer present for breathlessness (Overall SMD -0.22 , $95 \%$ CI $-0.46,0.02)$ or Quality of Life-Physical (Overall SMD 0.33, 95\% CI $-0.02,0.69$ ). For the three health domains where CCTs contributed data, meta-regression indicated that compared to RCTs, CCTs did not significantly predict effect sizes (Table 1).

\section{Discussion}

The most recent GOLD guidelines ${ }^{4}$ propose that there is “ ... no evidence that anxiety and depression should be treated differently in the presence of COPD." There is a consistent evidence base supporting the positive impact of CBT on anxiety and/or depressive symptoms in both people with generalized anxiety and depressive disorders, and people living with COPD. In this review, there were small significant intervention effects favoring CBT across CCT/RCTs for all five health domains. When compared to usual care, high-intensity 
D Exercise Capacity

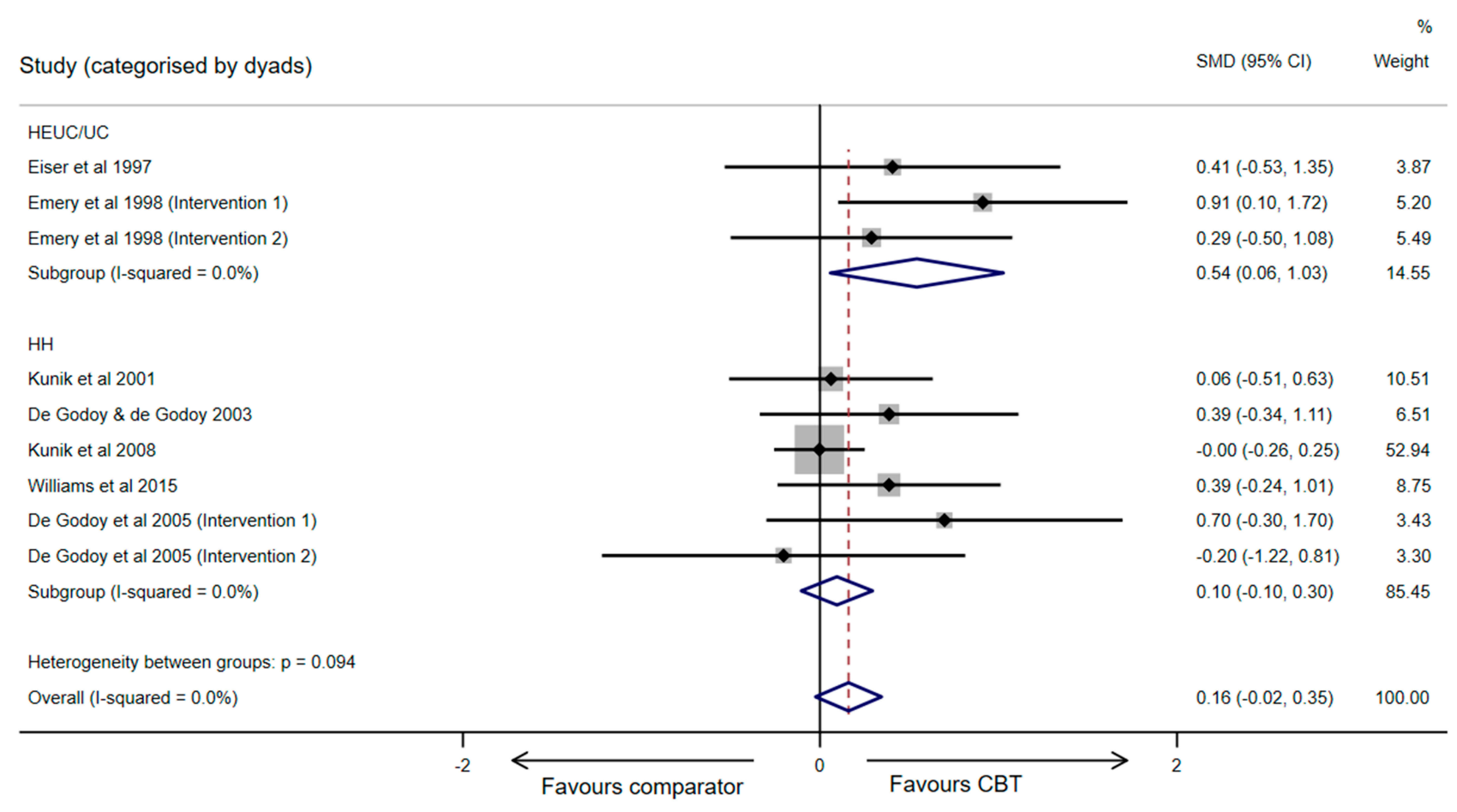

Figure I Continued.

CBT interventions consistently resulted in significant improvements in symptoms (anxiety, depression, breathlessness), quality of life and exercise capacity. However, when CBT interventions and comparators were of equally high resource intensity, there was less compelling evidence of benefit for CBT. Overall, there was negligible evidence that the specific focus of the CBT intervention, number of intervention sessions, facilitator profession, delivery mode, presence of co-morbid clinical anxiety/depression or sample size/study quality were associated with the effect sizes of health outcomes.

In our meta-analysis, heterogeneity varied across analyses for health outcomes where heterogeneity was considerable $\left(\mathrm{I}^{2}=75-100 \%\right)$ for Quality of Life-Physical (91.6\%, $\mathrm{n}=17$ studies), substantial $\left(\mathrm{I}^{2}=50-90 \%\right)$ for Anxiety $(70.5 \% \mathrm{n}=20$ studies) and Dyspnea $(70.7 \%, \mathrm{n}=7$ studies), moderate $\left(\mathrm{I}^{2}=30-60 \%\right)$ for Quality of life-Mental Wellbeing ( $44.8 \%, \mathrm{n}=16$ studies) and may have been unimportant $\left(\mathrm{I}^{2}=0-40 \%\right)$ for Depression $(24.1 \% \mathrm{n}=18$ studies) or Exercise capacity $(0.0 \%, n=7$ studies $)$. While noting that the $\mathrm{I}^{2}$ does not inherently depend upon the number of studies included in the analysis, this metric will be influenced by the combination of specific studies, composition of outcome measures and grouping of psychological interventions included in each analysis and hence will be "unique" to each analysis.

Consequently, compared to previous meta-analyses of similar health outcomes reported for CBT/psychological interventions in people with COPD, heterogeneity in our meta-analysis was similar to that reported for Anxiety (substantial heterogeneity $\mathrm{I}^{2}: 74.1 \%, \mathrm{n}=13$ studies, ${ }^{12} 80 \%, \mathrm{n}=4$ studies, ${ }^{8} 62 \%, n=3$ studies $^{9}$ ), Depression (unimportant heterogeneity $\mathrm{I}^{2}: 10.1 \%, \mathrm{n}=12$ studies, $^{12} 10.1 \%, \mathrm{n}=7$ studies, $^{7}$ $0.00, n=6$ studies $^{10}$ ) and Dyspnea (substantial heterogeneity $\mathrm{I}^{2}=59.5 \%, \mathrm{n}=9$ studies $^{12}$ ). Heterogeneity in our meta-analysis differed to that reported for Anxiety (moderate heterogeneity $\mathrm{I}^{2}=34.5 \%, \mathrm{n}=7$ studies $^{7}$ ), Depression (substantial heterogeneity $\mathrm{I}^{2}=74 \% \mathrm{n}=4$ studies $\left.^{8}\right)$, Quality of Life $\left(\mathrm{I}^{2}=56.3 \%, \mathrm{n}=16\right.$ studies $\left.^{12}\right)$ and Exercise capacity $\left(\mathrm{I}^{2}=64.4 \%, \mathrm{n}=10\right.$ studies $\left.^{12}\right)$.

In line with current health service strategies to provide the greatest availability of psychological interventions to people living with generalized anxiety, panic or depressive disorders, ${ }^{1,3}$ we opted to explore CBT interventions and comparators categorized as low- or high-resource intensity. In prior systematic reviews of psychological interventions for people with COPD, where sub-group meta-analyses are reported, these consider intervention type (CBT, mind-body, self-management, ${ }^{7,12}$ inclusion of exercise training ${ }^{7,11}$ or 


\section{$\mathbf{E}$}

\section{Quality of Life - Mental Wellbeing}

Study (categorised by dyads)

$\operatorname{SMD}(95 \% \mathrm{Cl}) \quad$ Weight

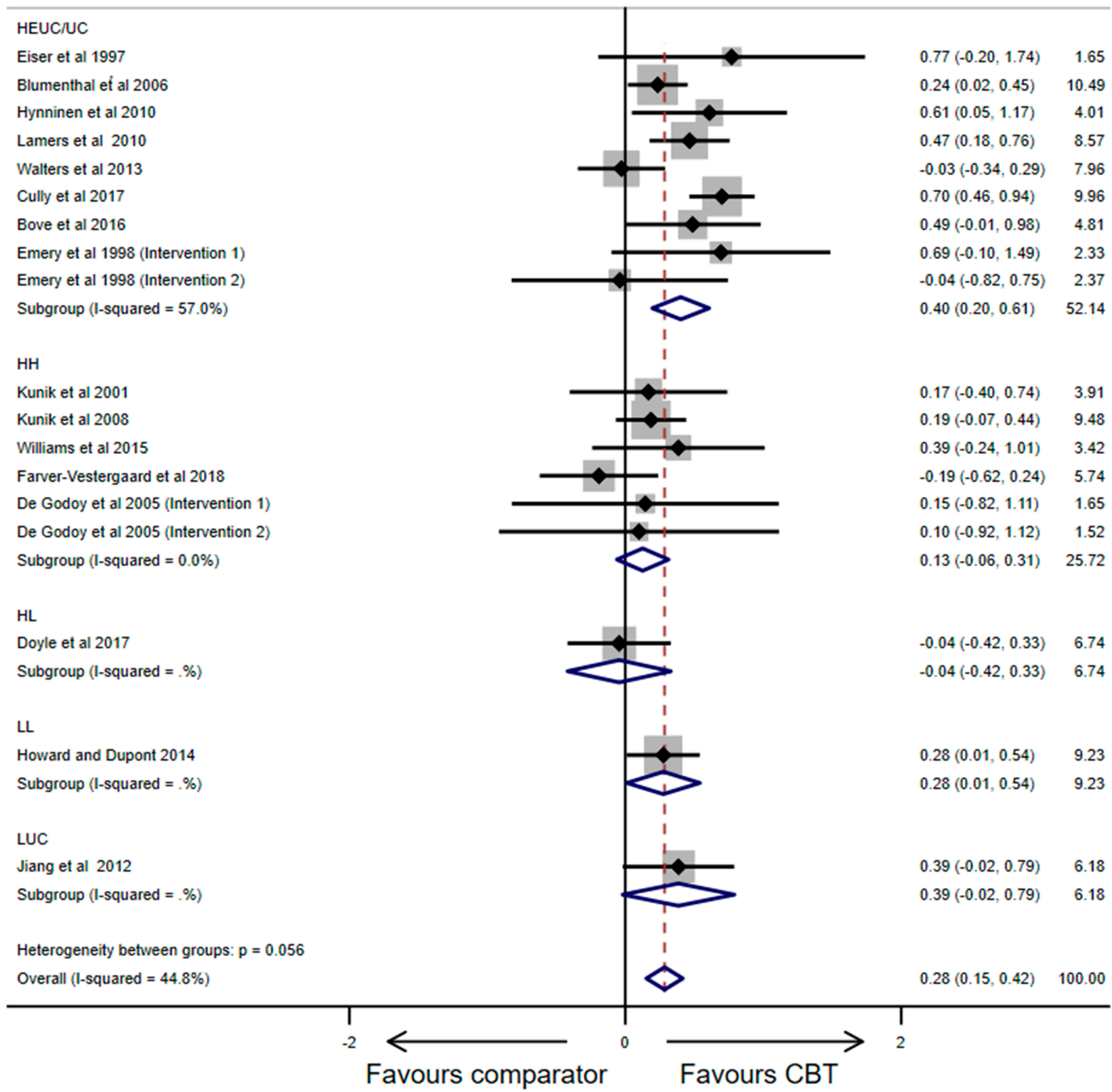

Figure I Continued.

severity of anxiety or depressive symptoms ${ }^{7}$ ). Few prior reviews provide sub-group meta-analysis concerning the nature of intervention-comparator dyads or predictors of intervention effect. Where such sub analyses have been reported in previous systematic reviews of people with COPD, our findings are consistent in that 1) CBT consistently produces a significant effect when compared to usual care; ${ }^{10-12} 2$ ) where active interventions are compared to active comparators, size and significance of the between-groups effect are diminished; ${ }^{12} 3$ ) the number of CBT sessions did not significantly predict effect size; ${ }^{12}$ and 4) CBT interventions showed similar benefit in those with confirmed or above-criterion 


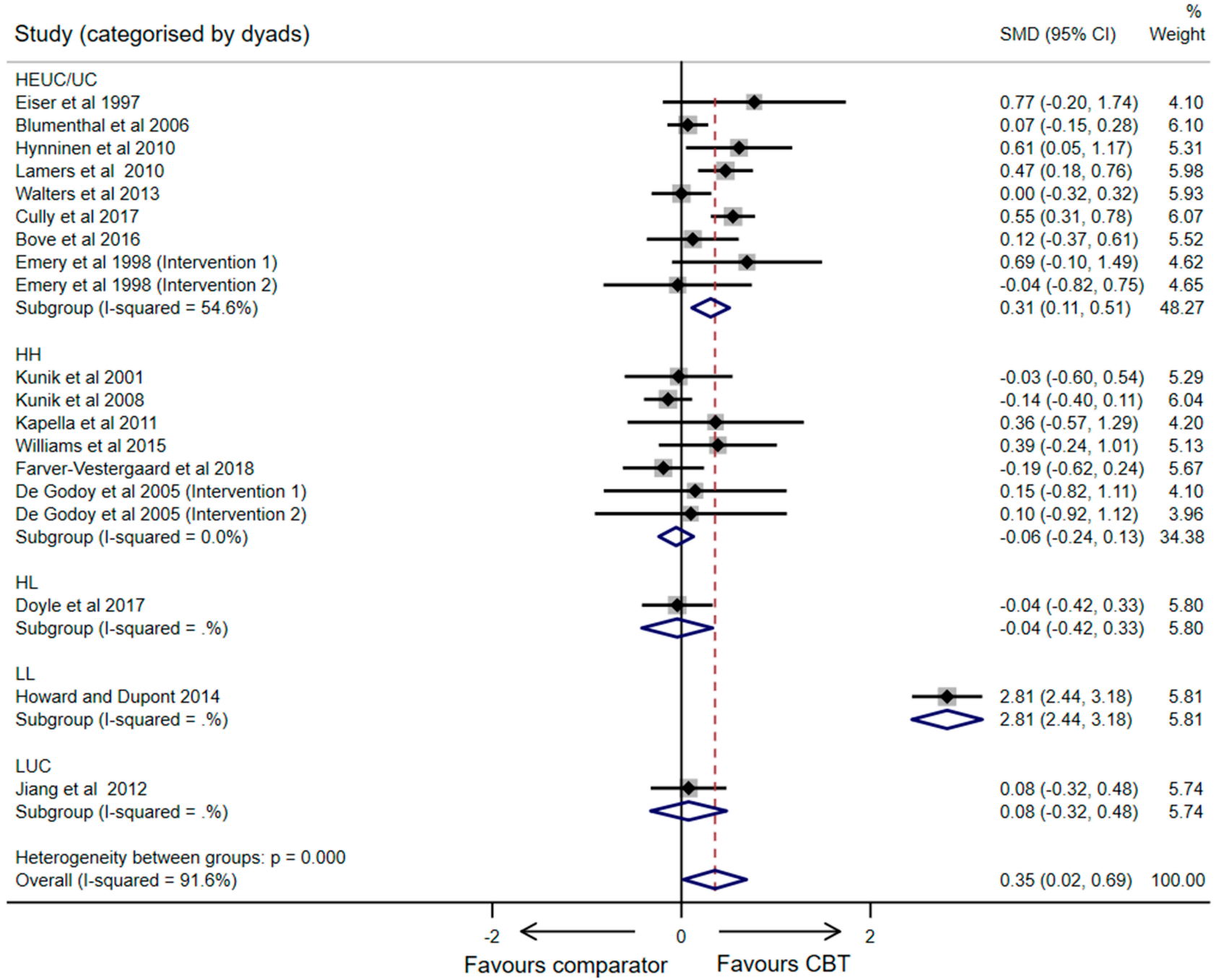

Figure I Effects of cognitive behavior therapy (CBT) interventions (random effects models) presenting overall effect and subgroup analysis for intensity dyads (A) Anxiety. (B) Depression. (C) Dyspnea (Breathlessness). (D) Exercise capacity. (E) Quality of Life (Mental Wellbeing). (F) Quality of Life (Physical).

Abbreviations: HEUC/EC, High intensity intervention compared to Enhance Usual Care/Usual care; HH, High-intensity intervention compared to High-intensity comparator; HL, High-intensity intervention compared to Low-intensity comparator; LL, Low-intensity intervention compared to Low-intensity comparator; LUC, Lowintensity intervention compared to Usual care (including Enhanced Usual Care where appropriate).

threshold scores and without co-existing anxiety and/or depression. ${ }^{7}$ These findings are not unique to CBT use in people living with COPD. Similar findings have been reported for CBT use in the older population with and without generalized anxiety or depressive disorders. ${ }^{33,34,66}$

Previous systematic reviews reporting meta-regression for CBT interventions in older people with and without COPD have included combinations of variables reflecting characteristics of the CBT intervention (ie, number of sessions, duration of program, individual or group), ${ }^{12,33,34,66}$ the comparator (passive or active), ${ }^{33,34}$ study quality (sample size, appraisal scores) ${ }^{12,33,34}$ and/or participants (age, sex, presence of anxiety/depression symptoms). ${ }^{12,33,34}$ Few variables have been identified which significantly predict effect sizes for CBT interventions (treatment durationlonger duration, smaller effect sizes ${ }^{34}$ ), type of control group (non-active vs active ${ }^{33}$ ), sessions per week $(>1$ per week ${ }^{66}$ ) and complexity of the CBT intervention (CBT augmented by motivational interviewing vs CBT alone ${ }^{33}$ ).

In people with COPD, the prevalence of psychological comorbidities, such as anxiety and depression and associations with poorer health outcomes are well recognized. Rationales for CBT interventions within this population are often based on the exertional breathlessness - breathing discomfort - anxiety - 


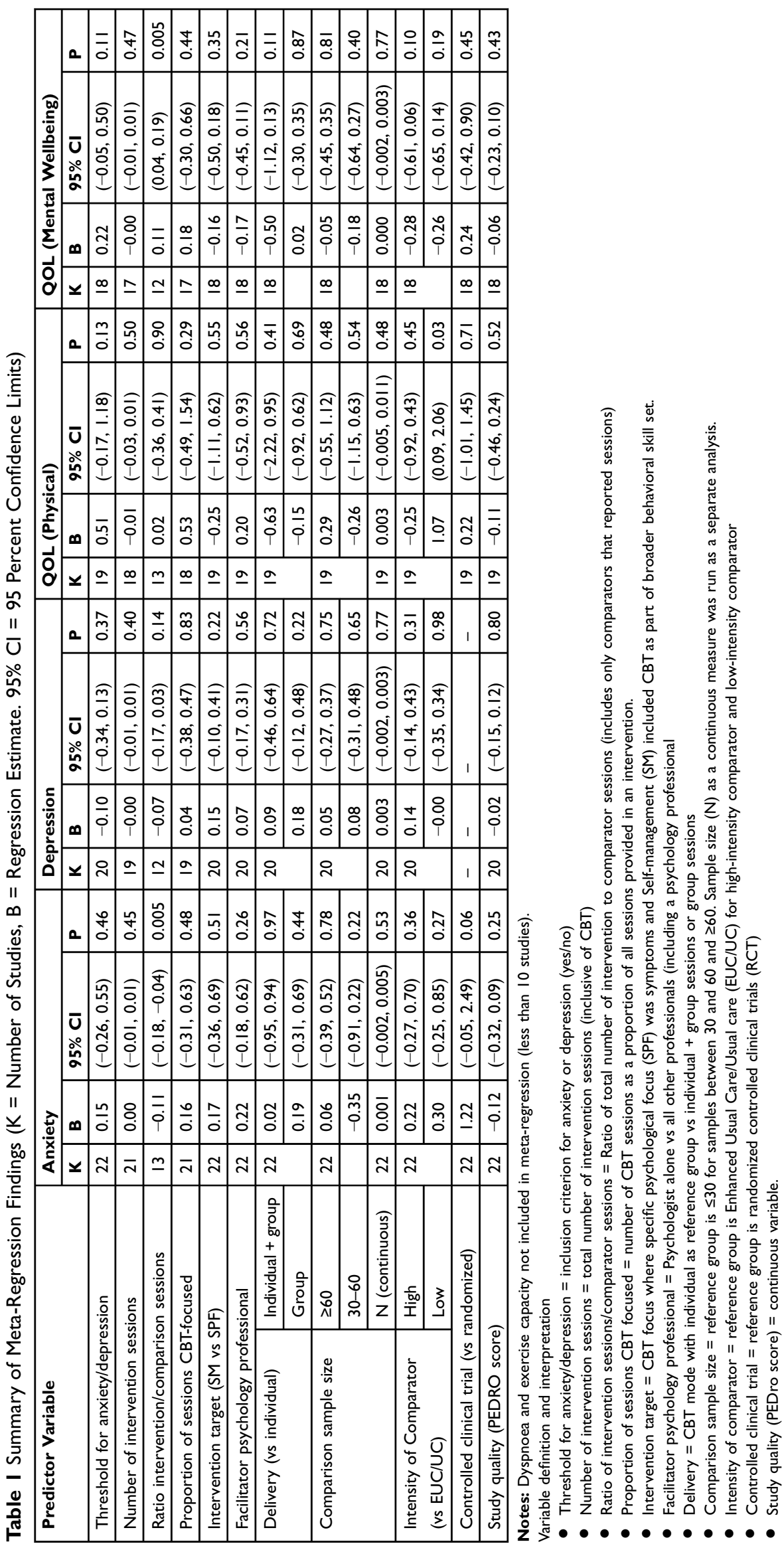


inactivity vicious cycle. Where people with COPD experience "breathlessness they find frightening" a cognitive behavioral component is recommended for inclusion within self-management plans to help reduce anxiety and distress. ${ }^{67}$ Yet the aetiology and pathophysiology of these psychological comorbidities is complex and likely includes interactions between biological (eg, systemic inflammation, hypoxia, ${ }^{68}$ cognitive/ perceptual (eg, symptom distress, illness intrusiveness, selfefficacy, mastery, coping strategies, learning capacity ${ }^{69,70}$ ) and sociodemographic factors ${ }^{71}$ (eg, income, access to health services, use of preventative health care, sex, high-risk health behaviors, comorbidities).

Of the CCT/RCTs included in this review $(\mathrm{n}=24)$, the most frequent comparator to CBT was EUC/UC $(n=12)$. While strategies used to balance time spent with participants were explicitly reported (eg, laboratory visits, ${ }^{37}$ phone calls, ${ }^{18,46}$ depression/anxiety assessments ${ }^{41}$ ), what constituted usual care was more opaque. In controlled trials within this review, UC was described as: standard care for $\mathrm{COPD},{ }^{18}$ the care usually received from their physicians, ${ }^{44,46}$ or medical center, ${ }^{19,41,48}$ according to relevant chronic disease clinical practice guidelines, ${ }^{20,43,47}$ or was not described. ${ }^{13,22,37}$ People with COPD receive less specialized medical care than people living with other chronic conditions ${ }^{72}$ and health professional knowledge of, and adherence to clinical practice guidelines specific to COPD have been estimated to be as low $6.7 \%$ for communitybased people living with $\mathrm{COPD}^{73}$ and range between $29.8 \%{ }^{73}$ and $36 \%$ for hospital-based registry data. ${ }^{74,75}$ The difficulty with interpreting comparisons between CBT and usual care lies in the absence of information concerning what constituted usual care, especially where key components of usual care might improve psychological outcomes.

Pulmonary rehabilitation (PR) is currently recommended as part of standard or usual care for people with COPD and has been confirmed to reduce symptoms of anxiety, depression, breathlessness and improve healthrelated quality of life and exercise capacity. ${ }^{4,23}$ Excluding direct comparisons of PR with and without CBT, four studies included explicit statements concerning the inclusion of PR as part of UC or a comparator ${ }^{19,40-43}$ with Bove et al ${ }^{43}$ Heslop-Marshall ${ }^{40}$ and Doyle et $\mathrm{al}^{42}$ reporting the proportion of people within the CBT and comparator groups participating in PR (past 12 months, CBT group $=45 \%$ vs UC group $=39 \% ;{ }^{43}$ completed prior to entry to study in CBT group $=33 \%$ vs self-help leaflet group $=36 \%$ or completed by end of study, CBT group $=46 \%$ vs $44 \%$ self-help leaflet group ${ }^{40}$ past or current attendance at PR clinic in CBT group $=65 \%$ vs
Befriending group $=80 \%{ }^{42}$ ). The potential for PR participation to confound the key findings was expressed by Doyle et al. ${ }^{42}$ In these three studies it is worth noting that where PR participation rates were higher for the CBT group, significant between-group effects were reported for anxiety (favoring CBT) at each post intervention time point ${ }^{40,43}$ and where PR participation rates were higher in the comparator group (Befriending), both groups improved and no significant between-group effect was reported for anxiety or depression. $^{42}$

Participation in PR is influenced by a wide range of individual (consumer ${ }^{76}$ and clinician ${ }^{77}$ ) and socio-environmental factors. ${ }^{78,79}$ While PR is recommended as usual care, poor referral, access and uptake rates suggest that for many people living with COPD, it continues to be "best or recommended practice" or "not quite usual practice." $\$ 0$

The second most frequent intervention-comparator dyad in this review were high-intensity interventions vs high-intensity comparators $(n=9)$, the most frequent of which concerned PR with or without $\mathrm{CBT}^{15,16,35,36,38}$ or mindfulness-based cognitive therapy $\left(\mathrm{MBCT}^{39}\right)$.

Anxiety and fear associated with physical exertion are common in people with COPD. ${ }^{81} \mathrm{PR}$ results not only in a physiological training response but as an individual's functional exercise capacity improves, provides opportunities for associative learning and reframing an individual's expectations concerning anxiety associated with activity. ${ }^{82}$

As PR includes exercise training under the direction of a health-care professional, this may address exertional breathlessness-related cognitive and emotional factors, even when CBT is not intentionally prescribed. There is significant overlap in components of CBT interventions listed in the included studies (eg,education on anxiety and COPD; education about depression and inactivity in COPD; distraction, relaxation, and breathing techniques; self-monitoring and goal setting) and common content of the education component of pulmonary rehabilitation (anxiety/depression and panic control management; symptom management including breathing strategies ${ }^{83}$ ). In both center- or home-based PR programs, ${ }^{84}$ individualized education and goal setting occurs during the supervised exercise sessions. ${ }^{85}$

This combination of functional exercise exposure with cognitive behavioral strategies, or "functional cognitive therapy" is recognized in the rehabilitation of disabling low-back pain $^{86}$ and has resulted in greater therapeutic benefits (reduced pain and disability) than exercise and manual therapy alone. ${ }^{87}$ These factors may explain why so few studies report significant changes in psychological health outcomes with the 
addition of specific CBT to comparators that include PR. However, the degree to which cognitive and emotional factors are addressed in PR is highly variable as this is not yet a standardized component of program delivery. ${ }^{88}$

The findings of this review support the value of CBT in targeting anxiety and depression for people with COPD but highlight that it may not be resource-wise to add when usual care includes high-intensity interventions, such as PR. Models such as integrated palliative and COPD care and breathlessness intervention services for people with advanced disease already incorporate CBT. ${ }^{89}$ While these services provide alternative opportunities for delivery of improved health outcomes, these models are not yet widely available. Given the risk that PR (with its capacity to deliver aspects of CBT) may not be accessible to all with COPD in low-resource environments, further investment in targeting, development, delivery of low-intensity CBT is indicated. In our analysis, associations with effect sizes for Quality of Life-Physical (1.07, 95\% CI 0.09 , 2.06, $\mathrm{p}=0.03$ ) were stronger for low intensity comparators compared to EUC/UC. No such difference was found for high intensity comparators. In both the education component of PR and in CBT, multiple factors including learning ability influence benefit gained or not from such interventions and needs to be assessed in potential participants. ${ }^{70,85}$

Rapid reviews are not as methodologically stringent as systematic reviews and while we did not include a number of the standard methodological processes required for systematic reviews (comprehensive search of databases, appraisal of publication bias), we worked to an a priori protocol and where possible, we endeavored to strengthen and transparently report our process. ${ }^{90}$ We used a pragmatic definition for CBT and included studies if they were self-described as CBT or based on CBT principles, rather than screen each intervention against a specific set of criteria. Our classification of interventions/comparators into high- or low-resource intensity, while in line with current psychological health services initiatives, is a very blunt approach with misclassification potential for a small number of studies. We included all data where available (reported or could be calculated) but both the meta-analysis and meta-regression are limited by small samples sizes and limited availability of health outcomes such as breathlessness and exercise capacity.

\section{Conclusion}

The intent of CBT is to assist individuals to identify and develop strategies to address problematic cognitions related to specific symptoms. The evidence base for use of CBT in people living with COPD is modest but growing. The analysis presented in this review confirmed that 1) compared to usual care, high-resource intensive CBT consistently resulted in small but significant reductions in symptom burden (anxiety, depression, breathlessness) and improved exercise capacity and quality of life; 2) embedding CBT within high-resource intensive, complex interventions did not confer additional health benefits, potentially as these include forms of covert CBT as part of personalized education, behavioral goal setting with or without direct adverse symptoms exposure, and 3) in general, the presence of anxiety/depressive symptoms, delivery mode or dosage of the CBT intervention did not overtly influence the size of the intervention effect. Given the dearth of specific studies (qualitative and experimental) of low-resource CBT identified within this review and the implications for health-care resources, especially for people with COPD without access to or participating in recommended care, exploration of low-intensity CBT against similar intensity interventions and/or usual care warrants further investment.

\section{Author Contributions}

MTW initiated the original concept for this review; all authors contributed to the design and development of the final framework; data acquisition was completed by MTW and $\mathrm{CP}$, data analysis was undertaken by $\mathrm{CP}$ with MTW and KNJ contributing to interpretation. All authors contributed to data analysis, drafting or revising the article, gave final approval of the version to be published, and agree to be accountable for all aspects of the work.

\section{Disclosure}

The authors report no conflicts of interest in this work.

\section{References}

1. National Institute for Health and Care Excellence [NICE]. Generalised Anxiety Disorder and Panic Disorder in Adults: Management. Clinical guideline Published; January 26, 2011. [updated July 2019].

2. Australian Psychological Association. Evidence-Based Psychological Interventions in the Treatment of Mental Disorders: A Literature Review. 4th ed. The Australian Psychological Society Limited (APS); 2018.

3. Andrews G, Bell C, Boyce P, et al. Royal Australian and New Zealand College of Psychiatrists clinical practice guidelines for the treatment of panic disorder, social anxiety disorder and generalised anxiety disorder. Aust N Z J Psychiatry. 2018;52(12):1109-1172. doi:10.1177/ 0004867418799453

4. Global Initiative for Chronic Obstructive Lung Disease (GOLD). Global strategy for the diagnosis, management and prevention of COPD. 2020. Available from: http://www.goldcopd.org/. Accessed October 24th, 2019. 
5. Baraniak A, Sheffield D. The efficacy of psychologically based interventions to improve anxiety, depression and quality of life in COPD: a systematic review and meta-analysis. Patient Educ Couns. 2011;83(1):29-36. doi:10.1016/j.pec.2010.04.010

6. Fritzsche A, Clamor A, von Leupoldt A. Effects of medical and psychological treatment on depression in patients with COPD - A review. Respir Med. 2011;105:1422-1433. doi:10.1016/j.rmed.2011.05.014

7. Coventry PA, Bower P, Keyworth C, et al. The effect of complex interventions on depression and anxiety in chronic obstructive pulmonary disease: systematic review and meta-analysis. PLoS One. 2013;8(4):e60532. doi:10.1371/journal.pone.0060532

8. Smith SMS, Sonego S, Ketcheson L, et al. A review of the effectiveness of psychological interventions used for anxiety and depression in chronic obstructive pulmonary disease. BMJ Open Respir Res. 2014;1(1):e000042. doi:10.1136/bmjresp-2014-000042

9. Usmani ZA, Carson KV, Heslop K, Esterman AJ, De Soyza A, Smith BJ. Psychological therapies for the treatment of anxiety disorders in chronic obstructive pulmonary disease. Cochrane Database Syst Rev. 2017. 3. doi:10.1002/14651858.CD010673.pub2

10. Pollok J, van Agteren JEM, Esterman AJ, Carson-Chahhoud KV. Psychological therapies for the treatment of depression in chronic obstructive pulmonary disease. Cochrane Database Syst Rev. 2019. 3. doi:10.1002/14651858.CD012347.pub2

11. Wiles L, Cafarella P, Williams MT. Exercise training combined with psychological interventions for people with chronic obstructive pulmonary disease. Respirology. 2015;20:46-55. doi:10.1111/resp.12419

12. Farver-Vestergaard I, Jacobsen D, Zachariae R. Efficacy of psychosocial interventions on psychological and physical health outcomes in Chronic Obstructive Pulmonary Disease: a systematic review and meta-analysis. Psychother Psychosom. 2015;84(1):. doi:10.1159/000367635

13. Emery CF, Schein RL, Hauck ER, MacIntyre NR. Psychological and cognitive outcomes of a randomized trial of exercise among patients with chronic obstructive pulmonary disease. Health Psychol. 1998;17 (3):232-240. doi:10.1037/0278-6133.17.3.232

14. Kunik ME, Braun U, Stanley MA, et al. One session cognitive behavioral therapy for elderly patients with chronic obstructive pulmonary disease. Psychol Med. 2001;31:717-723. doi:10.1017/ S0033291701003890

15. de Godoy DV, de Godoy RF. A randomized controlled trial of the effect of psychotherapy on anxiety and depression in chronic obstructive pulmonary disease. Arch Phys Med Rehabil. 2003;84:1154-1157. doi:10.1016/S0003-9993(03)00239-9

16. de Godoy DV, de Godoy RF, Becker Ju'nior B, et al. The effect of psychotherapy provided as part of a pulmonary rehabilitation program for the treatment of patients with chronic obstructive pulmonary disease. J Bras Pneumol. 2005;31:499-505

17. Kunik M, Veazey C, Cully J, et al. COPD education and cognitive behavioral therapy group treatment for clinically significant symptoms of depression and anxiety in COPD patients: a randomized controlled trial. Psychol Med. 2008;38:385-396. doi:10.1017/ S0033291707001687

18. Hynninen MJ, Bjerke N, Pallesen S, Bakke PS, Nordhus IH. A randomized controlled trial of cognitive behavioral therapy for anxiety and depression in COPD. Respir Med. 2010;104:986-994. doi:10.1016/j.rmed.2010.02.020

19. Livermore N, Sharpe L, McKenzie D. Prevention of panic attacks and panic disorder in COPD. Eur Respir J. 2010;35:557-563. doi:10.1183/09031936.00060309

20. Lamers F, Jonkers CCM, Bosma H, et al. Improving quality of life in depressed COPD patients: effectiveness of a minimal psychological intervention. COPD. 2010;7:315-322. doi:10.3109/15412555.2010.510156

21. Kapella MC, Herdegen JJ, Perlis ML, et al. Cognitive behavioral therapy for insomnia comorbid with COPD is feasible with preliminary evidence of positive sleep and fatigue effects. Int J Chron Obstruct Pulmon Disease. 2011;6:625-635. doi:10.2147/COPD. S24858
22. Jiang $\mathrm{X}, \mathrm{He} \mathrm{G}$. Effects of an uncertainty management intervention on uncertainty, anxiety, depression, and quality of life of chronic obstructive pulmonary disease outpatients. Res Nurs Health. 2012;35(4):409418. doi:10.1002/nur.v35.4

23. Yang IA, Brown JL, George J et al. The COPD-X Plan: Australian and New Zealand Guidelines for the management of Chronic Obstructive Pulmonary Disease 2019. Version 2.59, August 2019. Accessed November 14th, 2019. Available from: https://copdx.org. au/copd-x-plan/.

24. Williams MT, Effing TW, Paquet C, et al. Counseling for health behavior change in people with COPD: systematic review. Int $J$ Chron Obstruct Pulmon Disease. 2017;12:2165-2178. doi:10.2147/ COPD.S111135

25. Parshall MB, Schwartzstein RM, Adams L, et al. An official American Thoracic Society statement: update on the mechanisms, assessment, and management of dyspnea. Am J Respir Crit Care Med. 2012;185:435-452. doi:10.1164/rccm.201111-2042ST

26. Sutton K, Cooper M, Pimm J, et al. Anxiety in chronic obstructive pulmonary disease: the role of illness specific catastrophic thoughts. Cognit Ther Res. 1999;23:573-585. doi:10.1023/A:1018780623406

27. Wigal JK, Greer TL, Kotses H. The COPD self-efficacy scale. Chest. 1991;99:1193-1196. doi:10.1378/chest.99.5.1193

28. Rohatgi A. Web plot digitizer [computer program]. Version 3.11 Austin, TX; 2017.

29. de Morton NA. The PEDro scale is a valid measure of the methodological quality of clinical trials: a demographic study. J Physiother. 2009;55:129-133.

30. Maher CG, Sherrington C, Herbert RD, Moseley AM, Elkins M. Reliability of the PEDro scale for rating quality of randomized controlled trials. Phys Ther. 2003;83(8):713-721. doi:10.1093/ptj/83.8.713

31. Harbord R, Higgins J. METAREG: stata module to perform metaanalysis regression. Statistical Software Components S446201, Boston College Department of Economics, 2004, Revised January 05, 2009.

32. Higgins JPT, Green S, editors. Cochrane Handbook for Systematic Reviews of Interventions Version 5.1.0. The Cochrane Collaboration; 2011. [updated March]. Available from: www.handbook.cochrane. org.

33. Gould RL, Coulson MC, Howard RL. Efficacy of cognitive behavioral therapy for anxiety disorders in older people: a meta-analysis and meta-regression of randomized controlled trials. J Am Geriatr Soc. 2012;60(2):218-229. doi:10.1111/j.1532-5415.2011.03824.x

34. Zhang A, Borhneimer LA, Weaver A, et al. Cognitive behavioral therapy for primary care depression and anxiety: a secondary metaanalytic review using robust variance estimation in meta-regression. $J$ Behav Med. 2019;42:1117-1141. doi:10.1007/s10865-019-00046-z

35. Luk EK, Gorelik A, Louis I, Fary K. Effectiveness of cognitive behavioral therapy in a community-based pulmonary rehabilitation programme: A controlled clinical trial. J Rehabil Med. 2017;49 (3):264-269. doi:10.2340/16501977-2189

36. Williams MT, Cafarella P, Paquet C, Frith P. Cognitive Behavioral Therapy for management of dyspnea: A pilot study. Respir Care. 2015;60(9):1303-1313. doi:10.4187/respcare.03764

37. Eiser N, West C, Evans S, Jeffers A, Quirk F. Effects of psychotherapy in moderately severe COPD: a pilot study. Eur Respir J. 1997;10 (7):1581-1584. doi:10.1183/09031936.97.10071581

38. Pumar MI, Roll M, Fung P, et al. A cognitive behavioural therapy (CBT) for patients with chronic lung disease and psychological comorbidities undergoing pulmonary rehabilitation. J Thorac Dis. 2019;11(Suppl 17):S2238-S2253. doi:10.21037/jtd.2019.10.23

39. Farver-Vestergaard I, O’Toole MS, O’Connor M, et al. Mindfulnessbased cognitive therapy in COPD: a cluster randomised controlled trial. Eur Respir J. 2018;51(2):1702082. doi:10.1183/13993003.020 82-2017

40. Heslop-Marshall K, Baker C, Carrick-Sen D, et al. Randomised controlled trial of cognitive behavioural therapy in COPD. ERJ Open Res. 2018;4:00094-2018. doi:10.1183/23120541.00094-2018 
41. Cully JA, Stanley MA, Petersen NJ, et al. Delivery of brief cognitive behavioral therapy for medically ill patients in primary care: pragmatic randomized clinical trial. J Gen Intern Med. 2017;32(9):10141024. doi:10.1007/s11606-017-4101-3

42. Doyle C, Bhar S, Fearn M, et al. The impact of telephone-delivered cognitive behaviour therapy and befriending on mood disorders in people with chronic obstructive pulmonary disease: a randomized controlled trial. Br J Health Psychol. 2017;22:542-556. doi:10.11 11/bjhp.2017.22.issue-3

43. Bove D, Lomborg K, Jensen AK, Overgaard D, Lindhardt BO, Midtgaardet J. Efficacy of a minimal home-based psychoeducative intervention in patients with advanced COPD: A randomised controlled trial. Respir Med. 2016;121:109-116. doi:10.1016/j.rmed. 2016.11.009

44. Lee H, Yoon Y, Lim Y, et al. The effect of nurse-led problem-solving therapy on coping, self efficacy and depressive symptoms for patients with chronic obstructive pulmonary disease: a randomised controlled trial. Age Ageing. 2015;44:397-403. doi:10.1093/ageing/afu201

45. Howard C, Dupont S. The COPD breathlessness manual: a randomised controlled trial to test a cognitive-behavioural manual versus information booklets on health service use, mood and health status, in patients with chronic obstructive pulmonary disease. NPJ Prim Care Respir Med. 2014;24:14076. doi:10.1038/npjpcrm.2014.76

46. Walters J, Cameron Tucker H, Wills K, et al. Effects of telephone health mentoring in community recruited chronic obstructive pulmonary disease on self-management capacity, quality of life and psychological morbidity: a randomised controlled trial. BMJ Open. 2013;3:e003097. doi:10.1136/bmjopen-2013-003097

47. Jonkers CCM, Lamers F, Bosma H, Metsemakers JFM, van Eijk JTM. The effectiveness of a minimal psychological intervention on self-management beliefs and behaviors in depressed chronically ill elderly persons: a randomized trial. Int Psychogeriatr. 2012;24 (2):288-297. doi:10.1017/S1041610211001748

48. Blumenthal JA, Babyak MA, Carney RM, et al. Telephone-based coping skills training for patients awaiting lung transplantation. $J$ Consult Clin Psychol. 2006;74:535-544. doi:10.1037/0022-006X.74.3.535

49. Lisansky DP, Clough DH. A cognitive-behavioral self-help educational program for patients with COPD. A pilot study. Psychother Psychosom. 1996;65(2):97-101. doi:10.1159/000289054

50. de Godoy RF, Zimermann Teixeira PJ, Becker Ju'nior B, Michelli M, de Godoy DV. Long-term repercussions of a pulmonary rehabilitation program on the indices of anxiety, depression, quality of life and physical performance in patients with COPD. J Bras Pneumol. 2009;35:129-136. doi:10.1590/s1806-37132009000200005

51. Heslop K, de Soyza A, Baker CR, Stenton C, Burns GP. Using individualised cognitive behavioural therapy as a treatment for people with COPD. Nurs Times. 2009;105:14-17.

52. Cully JA, Stanley MA, Deswal A, Hanania NA, Phillips LL, Kunik ME. Cognitive-behavioral therapy for chronic cardiopulmonary conditions: preliminary outcomes from an open trial. Prim Care Companion J Clin Psychiatry. 2010;12(4):PCC.09m00896. doi:10.4088/PCC.09m00896blu

53. Howard C, Dupont S, Haselden B, Lynch J, Wills P. The effectiveness of group cognitive-behavioural breathlessness intervention on health status, mood and hospital admissions in elderly patients with chronic obstructive pulmonary disease. Psychol Health Med. 2010;15 (4):371-385. doi:10.1080/13548506.2010.482142

54. Farver-Vestergaard I, O'Connor M, Smith NC, Lokke A, Bendstrup E, Zachariae R. Tele-delivered mindfulness-based cognitive therapy in chronic obstructive pulmonary disease: a mixed-methods feasibility study. J Telemed Telecare. 2019;25(8):468-475. doi:10.1177/135 7633 X18780563

55. Stanley MA, Veazey C, Hopko D, Diefenbach G, Kunik ME. Anxiety and depression in chronic obstructive pulmonary disease (COPD): a new intervention and case report. Cognit Behav Pract. 2005;12:424 436. doi:10.1016/S1077-7229(05)80070-7
56. Cully JA, Paukert A, Falco J, Stanley M. Cognitive-behavioral therapy: innovations for cardiopulmonary patients with depression and anxiety. Cognit Behav Pract. 2009;16:394-407. doi:10.1016/j. cbpra.2009.04.004

57. Malpass A, Kessler D, Sharp D, Shaw A. MBCT for patients with respiratory conditions who experience anxiety and depression: A qualitative study. Mindfulness. 2015;6(5):1181-1191. doi:10.1007/ s12671-014-0370-7

58. Malpass A, Feder G, Dodd JW. Understanding changes in dyspnoea perception in obstructive lung disease after mindfulness training. BMJ Open Respir Res. 2018;5(1):e000309. doi:10.1136/bmjresp2018-000309

59. Ecker AH, Johnson AL, Sansgiry S, et al. Brief cognitive behavioral therapy reduces suicidal ideation in veterans with chronic illnesses. Gen Hosp Psychiatry. 2019;58:27-32. doi:10.1016/j.genhosppsych.2019. 02.002

60. Renn BN, Hundt NE, Sansgiry S, et al. Integrated brief cognitive behavioral therapy improves illness intrusiveness in veterans with chronic obstructive pulmonary disease. Ann Behav Med. 2018;52 (8):686-696. doi:10.1093/abm/kax045

61. Livermore N, Dimitri A, Sharpe L, McKenzie DK, Gandevia SC, Butler JE. Cognitive behaviour therapy reduces dyspnoea ratings in patients with chronic obstructive pulmonary disease. Respir Physiol Neurobiol. 2015;216:35-42. doi:10.1016/j.resp.2015.05.013

62. Schüz N, Walters JAE, Cameron-Tucker H, Scott J, Wood-Baker R, Walters EH. Patient anxiety and depression moderate the effects of increased self-management knowledge on physical activity: a secondary analysis of a randomised controlled trial on health-mentoring in COPD. COPD. 2015;12(5):502-509. doi:10.3109/15412555.2014.995289

63. Moayeri F, Dunt D, Hsueh YA, Doyle C. Cost-utility analysis of telephone-based cognitive behavior therapy in chronic obstructive pulmonary disease (COPD) patients with anxiety and depression comorbidities: an application for willingness to accept concept. Expert Rev Pharmacoecon Outcomes Res. 2019;19(3):331-340. doi:10.1080/14737167.2019.1536550

64. Hundt N, Renn BN, Shubhada S, et al. Predictors of response to brief CBT in patients with cardiopulmonary conditions. Health Psychol. 2018;37(9):866-873. doi:10.1037/hea0000595

65. Bove DG, Midtgaard J, Kaldan G, Overgaard D, Lomborg K. Homebased COPD psychoeducation: A qualitative study of the patients' experiences. J Psychosom Res. 2017;98:71-77. doi:10.1016/j. jpsychores.2017.05.013

66. Cuijpers P, Huibers M, Ebert DD, Koole SL, Andersson G. How much psychotherapy is needed to treat depression? A metaregression analysis. J Affect Disord. 2013;149(1-3):1-13. doi:10.1016/j.jad.2013.02.030

67. Chronic obstructive pulmonary disease in over 16s: diagnosis and management. NICE guideline [NG115]. [updated July 2019] December 2018.

68. Pumar MI, Gray CR, Walsh JR, Yang IA, Rolls TA, Ward DL. Anxiety and depression-Important psychological comorbidities of COPD. J Thorac Dis. 2014;6(11):1615-1631. doi:10.3978/j.issn. 2072-1439.2014.09.28

69. Thakur ER, Sansgiry S, Petersen NJ, et al. Cognitive and perceptual factors, not disease severity, are linked with anxiety in COPD: results from a cross-sectional study. Int J Behav Med. 2018;25:74-84. doi:10.1007/s12529-017-9663-2

70. Bruijniks SJE, DeRubeis RJ, Hollon SD, Huibers MJH. The potential role of learning capacity in cognitive behavior therapy for depression: A systematic review of the evidence and future directions for improving therapeutic learning. Clin Psychol Sci. 2019;7(4):668-692. doi:10.1177/2167702619830391

71. Stellefson M, Paige SR, Barry AE, Wang MQ, Apperson A. Risk factors associated with physical and mental distress in people who report a COPD diagnosis: latent class analysis of 2016 behavioral risk factor surveillance system data. Int J Chron Obstruct Pulmon Dis. 2019;14:809-822. doi:10.2147/COPD.S194018 
72. Mecredy GC, Wong HH, Stanbrook MB, Gershon AS. Which physicians are taking care of people with COPD? Chest. 2019;155 (4):771-777. doi:10.1016/j.chest.2018.12.018

73. Jouleh B, Erdal M, Eagan TM, Bakke P, Gulsvik A, Nielsen R. Guideline adherence in hospital recruited and population based COPD patients. BMC Pulm Med. 2018;18(1):195. doi:10.1186/ s12890-018-0756-8

74. Chinai B, Hunter K, Roy S. Outpatient management of chronic obstructive pulmonary disease: physician adherence to the 2017 global initiative for chronic obstructive lung disease guidelines and its effect on patient outcomes. J Clin Med Res. 2019;11(8):556-562. doi:10.14740/jocmr3888

75. Mannino DM, Yu TC, Zhou H, Higuchi K. Effects of GOLDAdherent prescribing on COPD symptoms burden, exacerbations and health care utilization in a real-world setting. Chronic Obstr Pulm Dis. 2015;2(3):223-235. doi:10.15326/jcopdf.2.3.2014.0151

76. Keating A, Lee AL, Holland AE. Lack of perceived benefit and inadequate transport influence uptake and completion of pulmonary rehabilitation in people with chronic obstructive pulmonary disease: a qualitative study. J Physiother. 2011;57:183-190. doi:10.1016/ S1836-9553(11)70040-6

77. Johnston KN, Young M, Grimmer K, et al. Barriers to, and facilitators for, referral to pulmonary rehabilitation in COPD patients from the perspective of Australian general practitioners: a qualitative study. Prim Care Respir J. 2013;22:319-324. doi:10.4104/ pcrj.2013.00062

78. Singh S, Halpin D, Salvi S, Kirenga B, Mortimer K. Exercise and pulmonary rehabilitation for people with chronic lung disease in LMICs: challenges and opportunities. Lancet Respir Med. 2019;7 (12):1002-1004. doi:10.1016/S2213-2600(19)30364-9

79. Steiner M, Lowe D, Beckford K, et al. Socioeconomic deprivation and the outcome of pulmonary rehabilitation in England and Wales. Thorax. 2017;72:530-537. doi:10.1136/thoraxjnl-2016209376

80. Vogiatzis I, Rochester CL, Spruit MA, Troosters T, Clini EM. American Thoracic Society/European Respiratory Society Task Force on Policy in Pulmonary Rehabilitation. Increasing implementation and delivery of pulmonary rehabilitation: key messages from the new ATS/ERS policy statement. Eur Respir J. 2016;47(5):13361341. doi:10.1183/13993003.02151-2015
81. Farris SG, Abrante AM, Bond DS, Stabile LM, Wu WC. Anxiety and fear of exercise in cardiopulmonary rehabilitation. Patient and practitioner perspectives. J Cardiopulm Rehabil Prev. 2019;39(2):E9-E13. doi:10.1097/HCR.0000000000000401

82. Herigstad M, Faull OK, Hayen A, et al. Treating breathlessness via the brain: changes in brain activity over a course of pulmonary rehabilitation. Eur Respir J. 2017;50:1701029. doi:10.1183/13993 003.01029-2017

83. Roberts N, Kidd L, Kirkwood K, Cross J, Partridge M. A systematic review of the content and delivery of education in pulmonary rehabilitation programmes. Respir Med. 2018;145:161-181. doi:10.1016/ j.rmed.2018.11.002

84. Holland A, Mahal A, Hill C, et al. Home-based rehabilitation for COPD using minimal resources: a randomised, controlled equivalence trial. Thorax. 2017;72:57-65. doi:10.1136/thoraxjnl-2016208514

85. Blackstock F, Evans R. Rehabilitation in lung diseases: 'Education' component of pulmonary rehabilitation. Respirology. 2019;24:863870. doi:10.1111/resp.v24.9

86. O'Sullivan PB, Caneiro JP, O'Keeffe M, et al. Cognitive functional therapy: an integrated behavioral approach for the targeted management of disabling low back pain. Phys Ther. 2018. 98:408-423.

87. Fersum K, O’Sullivan P, Skouen JS, Smith A, Kvale A. Efficacy of classification-based cognitive functional therapy in patients with nonspecific chronic low back pain: a randomized controlled trial. Eur J Pain. 2013;17:916-928. doi:10.1002/ejp.2013.17.issue-6

88. Blackstock F, Lareau S, Nici L, et al. Chronic obstructive pulmonary disease education in pulmonary rehabilitation. An Official American Thoracic Society/Thoracic Society of Australia and New Zealand/ Canadian Thoracic Society/British Thoracic Society Workshop Report. Ann Am Thorac Soc. 2018;15:769-784. doi:10.1513/AnnalsATS.201804253WS

89. Maddocks M, Lovell N, Booth S, Man W, Higginson I. Palliative care and management of troublesome symptoms for people with chronic obstructive pulmonary disease. Lancet. 2017;390:988-1002. doi:10.1016/S0140-6736(17)32127-X

90. Haby M, Chapman E, Clark R, Barreto J, Reveiz L, Lavis J. What are the best methodologies for rapid reviews of the research evidence for evidence-informed decision making in health policy and practice: a rapid review. Health Res Policy Syst. 2016;14(1):83. doi:10.1186/ s12961-016-0155-7

\section{Publish your work in this journal}

The International Journal of COPD is an international, peer-reviewed journal of therapeutics and pharmacology focusing on concise rapid reporting of clinical studies and reviews in COPD. Special focus is given to the pathophysiological processes underlying the disease, intervention programs, patient focused education, and self management protocols. This journal is indexed on PubMed Central, MedLine and CAS. The manuscript management system is completely online and includes a very quick and fair peer-review system, which is all easy to use. Visit http://www.dovepress.com/testimonials.php to read real quotes from published authors. 